\title{
The Rise and Fall of Collective Identity: Understanding Antecedents and Inhibitors of Social Identification in Distributed Teams
}

\author{
Stephen McCarthy \\ University College Cork \\ Stephen.McCarthy@ucc.ie
}

\author{
Paidi O'Raghallaigh \\ University College Cork \\ P.OReilly@ucc.ie
}

\author{
Ciara Fitzgerald \\ University College Cork \\ CFitzgerald@ucc.ie
}

\author{
Frédéric Adam \\ University College Cork \\ FAdam@ucc.ie
}

\begin{abstract}
The diverse backgrounds of distributed team members can pose unique challenges during decision-making processes. Notable of these is the gradual emergence of social identities, where individuals seek to form new social groupings within the temporal context of a project. However, our understanding of social identity within distributed teams remains nascent. Drawing on Social Identity Theory (SIT) and in-depth case study findings, we investigate the impact of social identity on decision-making in a distributed healthcare systems development team. Contrary to SIT, we see the dissolution of distinct social groupings and rise of individualism within the project. Based on our findings, we discover five inhibitors which can impede social identification in distributed teams: role ambiguity, absence of a collective vision, transfer of ownership, lack of shared history, and incompatible personalities. We extend SIT to include antecedents of collective identities (e.g. distinctiveness, prestige, salience of outgroup), as well as inhibitors which foster individualism.
\end{abstract}

\section{Introduction}

Distributed teams can provide new opportunities for knowledge transfer by bringing together the complementary expertise of individuals from different organisational and geographical backgrounds [1]. In the healthcare sector for example, external IT developers are often hired to work with medical professionals and service operators in order to articulate service-level problems in the hospital, and design potential health information technology solutions to address them $[2,3$, 4]. Addressing organisational problems in such contexts can be an arduous task, one which often demands multidisciplinary engagement in uncertain and ill-structured decision-making practices [5, 6]. Collaboration between distributed team members therefore becomes vital for building the collective knowledge base needed to address the problem at hand $[7,8]$.

However, distributed teams are unlikely to have the shared context or shared history necessary to generate agreement early on due to their diverse professional, organisational, and disciplinary backgrounds $[9,10,11]$. This can create impediments during decision-making processes due to issues such as role ambiguity $[12,13]$ and differences in interests [6, 14]. For instance, IT professionals adept at following an agile methodology of systems development may prefer flat structures, whereas healthcare practitioners may value top-down structures where senior members are conferred with decision-making authority [15]. In addition, IT professionals may wish to pursue different agendas to healthcare practitioners: while IT professionals may be primarily interested in developing novel and innovative IT solutions, healthcare practitioners may be more technophobic due to concerns around patient outcomes and safety [15].

Social identity offers a lens for understanding how individuals interact in social environments and reconcile such differences $[12,16,17]$. Social identity refers to an individual's 'sense of self' which is typically formed within the collective of a social group. Previous studies suggest that an individual's social identity can impact decision-making processes by affecting their concern for other individuals' decision-making outcomes [18], shaping their decision-making preferences [19], and even maintaining commitment to faltering projects [20]. However, studies on social identity to date have primarily focused on established social groups in permanent organisational contexts (e.g. departments, divisions, professions) rather than temporarily established social groups (e.g. projects) [21]. Our understanding of how identity evolves in distributed project teams is still emerging. The temporal nature of projects, and the inherent diversity of distributed teams, have unique implications for identity and decisionmaking processes as the social groupings are emergent rather than historically established. Consequently, in order to explore these issues further, our paper seeks to 
address the following research question: how do social identities affect decision-making in distributed teams?

Our research adopts Social Identity Theory [12, 22] as a theoretical lens to investigate decision-making practices in distributed teams. We gathered qualitative empirical findings from the case study of a five-month information systems development project which sought to design a system for a hospital Intensive Care Unit (ICU) ward. This case study provided a fertile context for research as the project provided opportunities for the lead author to engage daily with the team and to gain insights into the varying perspectives and motivations of team members. The remainder of the paper is structured as follows: Section 2 describes the theoretical background, while Section 3 outlines the research design behind our case study research. Section 4 offers findings from the in-depth case study, and Section 5 presents a discussion of findings relative to the research question. Section 6 brings the paper to a close with a conclusion, description of contributions and future research.

\section{Theoretical Background}

Identity is a key feature of social contexts and is central to how individuals derive their 'sense of self' in the world [16, 23]. Identity shapes an individual's behaviours, perspectives, and emotions during team processes as well as their propensity for change [17, 23]. For example, individuals are more likely to accept change when it aligns with their sense of self. Identity is said to operate at two broad levels: individual identity which emerges from the network of roles and relationships that an individual is embedded in; and collective identity which emerges from an individual's membership of a social group [16, 17]. In-groups (i.e. a group that the individual identifies with) and out-groups (i.e. a group that the individual does not identify with) can develop over time [12] and both play a role in the emergence of collective identity. In addition, social identity is an emergent and evolving phenomenon may be subject to change over time. Research suggests have iterative development methods such as agile may better support collective (team-based) over individual (role based) identities through increased immersion and engagement [24]. Postmes, et al. [25] however suggest that communication forms may also play a role with organisational and work-related communications supporting the emergence of collective identities over and above interpersonal relationships.

In this paper, we adopt Social Identity Theory (SIT) $[12,22]$ as a lens to understand how identity-based differences (both individual and collective) contribute towards decision-making in distributed teams. SIT provides insights into how individuals cognitively segment themselves and others into different social groupings [22]. Social groupings are based on abstracted characteristics accepted by individuals that provide a systematic means of understanding identity in the social environment $[12,22]$. For example, one might identify with groupings based on job titles (e.g. "I'm a developer"), organisations (e.g. "I work for company $\mathrm{X}$ "), and professions (e.g. "I'm an expert in software development"). One might also identify with groupings based on geographic areas, gender, or age. Individuals can have multiple social identities associated with different social groups and assigned roles [26]. In their study of knowledge sharing in agile teams, Ghobadi and Mathiassen [27] found that team diversity (e.g. sense of identity) can lead to barriers relating to team perceptions (e.g. trust), and may cause team members to work more independently.

According to SIT, the social identification process is driven by three factors which create distinct social groupings: (i) Distinctiveness of group values relative to other groups, which in turns serves to differentiate one's sense of identity from others; (ii) Prestige of the group and how it links to the individual's sense of identity and self-esteem; and (iii) Salience of out-group whereby a strong collective identity arises when an out-group is present. Identity is relational and comparative, which means that one's identity can most easily be recognised in relation to that of others. For example, social identification will likely be more obvious in a multidisciplinary team of developers and clinicians, as professional differences between the groupings are more pronounced. Moreover, IT staff can only define and exert their identity if there are other non-IT staff working with them.

Within the research context of distributed project teams, there is considerable uncertainty around the emergence of social identification given that groupings within the project team are likely to be emergent rather than established. Distributed teams refer to collectives of individuals from different geographical, organisational, and disciplinary backgrounds [11, 28]. Distributed project teams also exist as subsystems within larger organisational contexts. This creates another layer of uncertainty around the relationship between established (organisational) and emergent (project-level) identities. Vahtera, et al. [29] study of virtual teams found that identification with an 'in-group' can create negative perceptions of a perceived 'outgroup' which in turn intergroup interactions and brokerage between team members. The lack of a shared history and context can also make individuals unsure of their roles in the team, role expectations, and power relations $[9,10,11]$. In these situations, social identification occurs and is reinforced through individuals constructing a situational definition [cf. 30] 
of behavioural norms. For example, a newcomer to an organisation will learn the norms of their working group through interactions with co-workers e.g. communication patterns, approaches to work, degrees of autonomy.

Figure 1 illustrates our conceptual model based on SIT and the work of Tajfel, et al. [22].

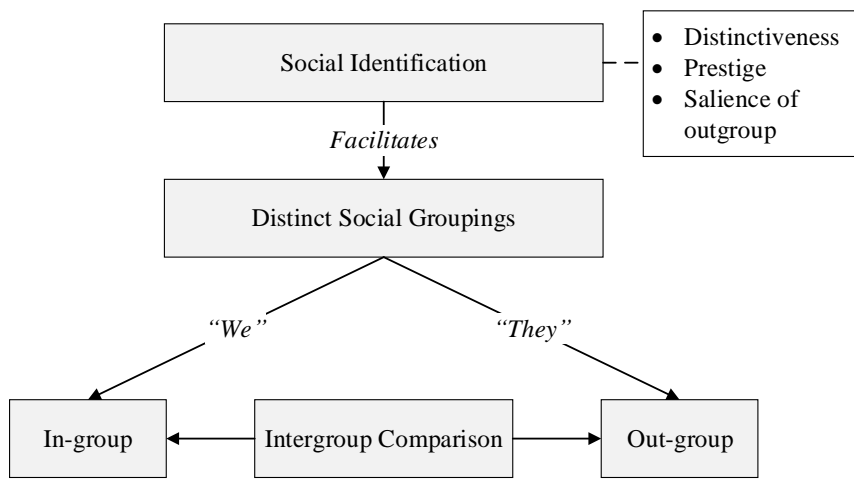

Figure 1: Conceptual Model (adapted from Tajfel, et al. [22])

The next section describes our research design which was based on an interpretivist case study research methodology.

\section{Research Design}

A case study [31, 32] was selected as the most appropriate research design for our study. Case study research can provide in-depth insights into the actions of individuals in a way that is not divorced from the context under investigation. This is particularly useful for investigating environments in which there are contested meanings, and phenomena that are non-linear, fragmented, and multi-dimensional such as social identity in distributed teams.

\subsection{Case Description}

The case study centres on a distributed information systems development project undertaken in a clinical setting. The project was a collaborative effort between practitioners working in one of the leading ICU wards in a country and staff in a prominent university research centre. The project involved the development of a Clinical Decision Support System (CDSS) to support decision making in the ICU. The software solution was to be evaluated for its effectiveness in improving patient outcomes. The solution consisted of a dashboard to display critical patient data, and an algorithm that simulated different care paths. This would allow the multi-disciplinary care teams to optimise patient treatment. The research study was to consist of a clinical investigation involving two cohorts (an intervention and control group) of 126 patients in the ICU ward.

The project team consisted of eight distributed team members, including: a Principal Investigator (PI), a postdoctoral researcher, an Intensive Care Unit (ICU) clinician, a research nutritionist, a clinical consultant (who assumed the role of clinical lead), a pharmacist, a research support officer, and an information systems developer. The clinical lead, ICU dietician, and pharmacist were active care providers in the ICU ward while the remainder of the team were employed in a university research centre. Industry partners provided financial support and benefit in kind (BIK) to the project but were not directly involved in the day to day execution of the project. These partners included a multinational company, a multinational pharmaceutical company, and a SME technology company.

\subsection{Data Collection and Analysis}

Data from the case study has been triangulated from the following three sources in order to increase the robustness of findings [cf. 33]: participant observations in the field, interviews with team members, and project documentation. Participant observations were conducted longitudinally over a period of five months (November to March) by the researcher (lead author). During this time the researcher was present in the team environment for two to three days a week, and attended project team meetings, typically lasting between an hour and three hours. Project documents and emails were also used to provide additional insights. The researcher conducted eight semi-structured interviews, each lasting between 45 minutes and an hour, with members of the multi-disciplinary team. Interviews were guided by SIT concepts. In particular, qualitative interviews centred on the following key questions for different groups:

- The team member's perceived role-based identity in the project.

- The prestige associated with different professional identities e.g. clinicians, scientists, developers.

- The team member's affiliation to a subgroup within the project team.

- The perceived distinctive characteristics of each subgroup.

- Salience of out-groups relevant to the subgroup that a team member feels affiliated with.

A large corpus of qualitative data gathered from the case study research was transcribed and anonymised. The transcribed interview data was analysed by the researcher (lead author) in order to identify and code variables such as concepts and properties, as well as the relationship between these variables. In particular, he 
adopted a directed approach to content analysis in which constructs from Social Identification Theory guided the initial codes of interest. This allowed him to analyze transcribed interview notes and organize findings into common themes. The analysis rested on the researcher's own interpretation of the phenomenon and the context in which it took place. Each sentence in the textual database was repeatedly read and a code book containing an inventory of codes and their descriptions was maintained to help structure the analysis. The researcher also sought to make assumptions and beliefs explicit during co-author meetings.

\section{Findings}

In this section, we present findings from the in-depth case study by drawing on SIT as a theoretical lens. The emergence of social identification in the project was initially driven by the respective organisational and disciplinary affiliations of team members, as distinct from their membership of the distributed team. The multi-disciplinary and collaborative nature of the project created clear delineations early on between team members' place of employment and their professional background. This resulted in three social groups emerging early on: a clinician group made up of healthcare practitioners working in the ICU ward of the local hospital, a scientists group consisting of academics working in the national university and affiliated to the research centre, and an intermediary group of project team members in the research centre who were responsible for supporting the development of the proposed CDSS solution and associated clinical guidelines. Table 1 outlines the members of these social groups, with quotations included to illustrate their social identification within the distributed team.

The findings also suggest that the geographical location of distributed team members (e.g. ICU ward, university campus, research centre) provided a shared context for social identification to emerge between certain team members - individuals who were co-located often had more opportunities for informal communication which supported the development of collective identities. For instance, the developer, research nutritionist, and project officer were all seated in close proximity to each other within the shared office space of the research centre and quickly formed social ties through spontaneous and regular interactions.

Consistent with SIT, the initial social groupings were facilitated by characteristics of distinctiveness, prestige, and salience of out-group [12, 22]. The proceeding paragraphs discuss the impact of each of these antecedents to social identification in turn.

Table 1. Initial Social Identities in the CDSS project.

\begin{tabular}{|c|c|c|}
\hline Social Group & Members & Quotations \\
\hline $\begin{array}{l}\text { 'Clinicians' } \\
\text { (ICU Ward) }\end{array}$ & $\begin{array}{l}\text { Pharmacist, } \\
\text { ICU } \\
\text { dietician, } \\
\text { clinical lead }\end{array}$ & $\begin{array}{l}\text { - "(I have) a clinical research role... (which applies) my expertise from } \\
\text { the clinical setting into the research setting." (ICU Dietician) } \\
\text { "Clinicians and researchers are very different. Clinicians are primarily } \\
\text { interested in the end result in terms of the applicability of (a solution) } \\
\text { in real time to the patients... you have different stresses as a clinician } \\
\text { with full time clinical responsibilities to the service and to individual } \\
\text { patients." (Clinical Lead) }\end{array}$ \\
\hline $\begin{array}{l}\text { 'Scientists' } \\
\text { (University } \\
\text { Campus) }\end{array}$ & $\begin{array}{l}\text { Principal } \\
\text { Investigator } \\
\text { (PI), } \\
\text { postdoctoral } \\
\text { researcher }\end{array}$ & $\begin{array}{l}\text { - "Clinicians aren't scientists so clinicians need to learn how to conduct } \\
\text { science from scientists. On the other side, scientists aren't clinicians." } \\
\text { (Principal Investigator) } \\
\text { - "the CDSS project differs because as far as I can see I'm probably one } \\
\text { of the only ones with a research background going into it." } \\
\text { (Postdoctoral researcher) }\end{array}$ \\
\hline $\begin{array}{l}\text { 'Intermediary' } \\
\text { (Research Centre) }\end{array}$ & $\begin{array}{l}\text { Developer, } \\
\text { Research } \\
\text { Nutritionist, } \\
\text { Project } \\
\text { Officer }\end{array}$ & $\begin{array}{l}\text { - "Clinicians have no clue of tech stuff. They're used to clinical work but } \\
\text { not IT... I'm the only one putting up the deadlines and forcing their } \\
\text { hands." (Developer) } \\
\text { "Through the conversations between (the developer) and I, we had } \\
\text { teased out what the project was about. It took a lot of time but now } \\
\text { we're at a place where we understand each other. That's the challenge } \\
\text { of the multidisciplinary involvement though, it took about } 6 \text { months for } \\
\text { us to get on the same page and you can't really factor that into a plan." } \\
\text { (Research Nutritionist) }\end{array}$ \\
\hline
\end{tabular}


First, there was a clear organisational distinction between the daily working relationship of the clinician group consisting of the pharmacist, ICU dietician, and clinical lead in the ICU ward, and the scientists group consisting of the PI and postdoctoral researcher who collaborated together regularly in the research centre. While the PI and ICU dietician had a prior working relationship, their grouping was less obvious given the primacy of the ICU ward as an implementation context. Distinctiveness was obvious when, for example, clinicians spoke about "our ICU" and the scientists spoke about their need for future research publications from the project. A further out-group formed among individuals who were hired specifically for the project but did not have prior relationships with members of the clinician or scientist groups.

Prestige also facilitated the emergence of social identification. As evident from some of the quotations in Table 1, membership of social groups was also a source of self-esteem for some team members. For example, clinicians believed that their disciplinary expertise was indispensable to the effective delivery of the study, while the scientists saw themselves as assuring the rigor of the research study. The prestige of the intermediary group was less clear initially, and the developer felt that despite being the only member with relevant IT expertise, his contributions were often unappreciated by the clinicians and scientists.

Finally, salience of out-group facilitated social identification as the multi-disciplinary nature of the project team created clear boundaries between each group. The developer was particularly conscious of outgroup saliency and at one point referred to his social identity as akin to a "team of one". Other team members also noted clear delineations between the expertise of clinicians and scientists, with out-group saliency affecting which individuals were given the most 'airtime' during clinical and academic discussions in meetings.

The emergence of social groups initially affected decision-making processes by localising certain decisions with only those considered 'in-siders' to a social group (e.g. clinicians) and limiting the opportunities for involvement by other team members. The pharmacist and ICU dietician often decided on the aspects of the research study and CDSS modelling separate to the rest of the team, with the resulting decisions later communicated to others. Similarly, the developer and research nutritionist made decisions around the data dictionary in isolation for others.

However, despite the formation of these social groupings early in the project, increasing uncertainty emerged as the groupings became more unstable. The remainder of the findings point towards inhibitors which impeded the stability of collective identities and social groupings later in the project.

\subsection{Role Ambiguity}

Despite the initial groupings, increasing uncertainty emerged over time around what each individual's role entailed, the boundaries of these roles, and their decision-making authority. As a result, some team members did not feel empowered to make decisions and felt uncertain about their decision making remit. This was particularly noticeable when more senior members such as the PI or clinical lead were absent from meetings due to obligations in their respective organisations. For example, at one meeting the developer and research nutritionist noted the absence of the PI and expressed their frustration at being unable to make calls around aspects of the software solution despite the tight deadline faced. In addition, role ambiguity emerged between the ICU dietician and research nutritionist as both assumed they had decision-making authority over the proposed ICU guidelines for the research study. This was due to the similar expertise they both shared, having previously held the same organisational role in different national hospitals. The ICU dietician asserted that she should have the 'final say' given that she was a key stakeholder for the research study however, the research nutritionist disagreed and felt her role was to finalise the guidelines. This led to them making separate decisions without consulting each other which served to create growing uncertainty within the team.

\subsection{Lack of a Collective Vision}

At the first meeting, the clinical lead declared that the project should only aim for incremental improvements to the effectiveness of operations in the ICU. He proudly felt that "[his] ICU" was well run and did not require significant changes. However, it later became clear that not everyone agreed with his position and felt that practices within the ICU should undergo more radical change. However, it seemed some of the changes proposed by other team members may have been motivated by their own individual interests. For example, the ICU dietician had a strong interest in digitalising, implementing, and testing an ICU modelling approach she developed as part of her $\mathrm{PhD}$ thesis. She felt that the software could increase her standing in the ICU ward: "this will be a real enhancement... the role of the dietician. Information is power and I think that it will be very useful". Meanwhile, the PI and postdoc researcher were mainly interested in the outputs from the research study and the prospect of scientific publications. However, in contrast, the developer noted that he was not interested in any 
future publications, or the ICU model developed by the ICU dietician, and his key motivation was to deliver a viable technology product that met the project's objectives. The research nutritionist also had a personal interest in improving the state of ICU practice in the local hospital and affecting real change.

\subsection{Transfer of Ownership}

The proposed system was to include an algorithm which would support clinical decision-making in the ward. To assist this, the developer had delegated the task of collecting data requirements to each team member as he felt that they were better placed to decide relevant data points given their disciplinary expertise. Nevertheless, ownership of the data dictionary (a document which outlined all the required data points) was seen by other team members to reside solely with the developer. Despite the developer's repeated requests for feedback on the requirements, communication from team members was slow coming. In response to the developer's dissatisfaction with these delays, the PI eventually mandated that team members needed to take ownership of the data requirements. However, the developer felt that the PI's instruction "fell on deaf ears". While other members of the team intermittently supported tasks related to software deliverables, the developer was still perceived as being responsible for its delivery. This increased the stress placed on the developer who felt that the success or otherwise of the solution rested solely on his individual ability and effort. This abdication of responsibility left the developer feeling frustrated and he pushed back on any late requirements: "put it down if you want it... Your decision, I'm quite happy to keep working away building software for another two years. You have a project to run so if you want [the additional requirement]... you have to make sure you really want it because that will add a month on top of everything else".

\subsection{Lack of Shared History}

While the developer sensed that the PI and ICU dietician knew the required data points, the team faced inherent difficulties in finalising decisions due to the tacit nature of disciplinary expertise and a lack of shared history. As noted by the PI: "The way we verbalise things is completely different to the way the developer does and vice versa". Engagement between the developer and the clinicians was helpful for clarifying some points of uncertainty around the purpose of the system, its requirements and how it should work in the ICU. However, knowledge gaps still remained and the developer became concerned that his access to the clinicians was 'patchy' and important decisions remained outstanding. Prior shared histories between other individuals also impacted the free transfer of knowledge in the project. For instance, the ICU dietician and clinical lead's long history of collaboration and professional relationship in the ICU impacted what could and could not be spoken about in meetings for 'sensitive' topics such as the recent implementation of the ICU's Electronic Health Record (EHR). The clinical lead had been deeply involved in the rollout of the EHR; therefore, conversations around the EHR were approached with caution by the ICU dietician in case their professional relationship would be affected by her views on the rollout. Conversations involving the EHR were more openly critical in the absence of the clinical lead. On the other hand, conversations were more reserved if the clinical lead was present or if there was a risk that they would be overheard. This was problematic for the developer in that he was hearing contradictory information at meetings depending on which individuals were present.

\subsection{Incompatible Personalities}

The clinical lead was initially perceived as the project's primary stakeholder given his seniority in the ICU and his dominant presence was felt during decision-making process at the initial team meetings. The clinical lead often displayed the personality trait of extraversion (outgoing and energetic) during meetings, speaking up to assert exactly what the project should and should not deliver. However, when the clinical lead's engagement with the project reduced for a period of three months, there was a noticeable change in the team dynamic. During this time, the ICU dietician became more influential and assumed a more senior position as she asserted what she felt the project should deliver. Meanwhile, the developer alternated between traits of confidence and nervousness in regard to the project outcomes. In private conversations, the developer was nervous that the aforementioned transfer of ownership could become problematic later, and was particularly concerned that decisions taken in the absence of the clinical lead might be reversed if and when he reengaged with the project. However, in team meetings, he remained confident when others enquired if development work was on schedule, asserting that "we will design for whatever people want". The developer also showcased the personality trait of cautiousness, during meetings by constantly challenging the assumptions of clinicians and scientists, and warning them about the consequences that would arise if their decision were based on false assumptions e.g. risks associated with the new ICU guideline, and confounding issues in the research study. Others found the developer's preoccupation with failure to be 
frustrating and felt that "we've been talking about hypothetical situations for too long". The PI exhibited the personality traits of conscientiousness (efficient) and became impatient with the developer's need for certainty around different issues: "some people will endlessly discuss an issue and others will try and action something. I found it a bit frustrating at times when conversations seemed to be very circular and... it took a long time to move on from an issue".

\section{Discussion}

This section provides a discussion of the findings from the project, particularly in relation to how social identities affect decision-making in distributed teams. Initially, social groupings in the project were seen to emerge from individuals' prior organisational and disciplinary affiliations. Consistent with SIT, we find that these social groupings were facilitated early on by the characteristics of distinctiveness, prestige, and salience of out-group [12, 22], and created well defined delineations between members of the distributed team. However, contrary to SIT, we later saw the rise of individualism within the distributed team, as distinct social groupings started to dissolve.

Several factors were found to contribute towards this dissolution. Firstly, role ambiguity challenged the prior social groupings as individuals became increasingly uncertain of their place in the team and within their social group. Role ambiguity is a common feature of complex social groupings such as distributed teams, as the absence of clearly established roles means that individuals' understanding of their decision-making authority must emerge through interactions [12, 13]. As a result, the team members began to seek out their own individual roles which often were in conflict (e.g. ICU dietician and research nutritionist).

Our findings also show how rifts within the clinician group emerged due to the lack of a collective vision in the distributed team, as the ICU dietician began to reverse decisions previously made unilaterally by the clinical lead. Prior research suggests that a shared vision supports the cohesiveness of distributed teams and creates a shared sense of purpose and shared ownership among different groups [34, 35].

The absence of a collective vision in the project also contributed towards the perceived transfer of ownership within the team and rise of individualism. For instance, the developer felt that team members had transferred ownership of tasks associated with systems development to him and that they abdicated responsibility for providing their disciplinary data requirements. The developer therefore increasingly viewed himself as "a team of one" and felt more and more isolated within the distributed team.

In addition, a lack of shared history was found to impede collective identity and knowledge transfer in the team. Despite distributed teams being advantageous for capitalising on diverse areas of expertise, the absence of a shared history of collaboration can raise uncertainties in their performance due to issues in resolving cultural and organisational differences [36]. This was seen in our case study during discussions between the developer and clinicians where progress was often slow. On the other hand, the presence of shared histories can also impede knowledge sharing due to perceptions around 'sensitive topics' for discussion. For instance, the ICU dietician hesitated to comment on the EHR implemented by the clinical lead when he was present due to concerns about their relationship. Similarly, literature has also suggested that work-related communications better support collective identity over and above inter-personal relationships [25].

Finally, differences in the personality traits of team members contributed towards individualism and the dissolution of social groups. Traits associated with the OCEAN framework [37] (e.g. Openness, Conscientiousness, Extraversion, Agreeableness, and Neuroticism) seemed to affect team dynamics at different points in time during the case study. Recent research has posited an indirect relationship between personality composition and team performance in virtual teams [38], and the emergence of leadership [38, 39]. In the project, the extraverted personalities of the clinical lead and ICU dietician resulted in power struggles around the inclusion or exclusion of different system requirements. This resulted in other team members 'taking sides' and thereby contributing to further breakdown of collectives. The developer's cautiousness (openness to experience) and PI's desire for efficiency (contentiousness) also impeded social identification as his continuous questioning around system requirements became a source of frustration for the PI and other team members.

Based on these findings, we can therefore point towards several inhibitors which impede the emergence of social groupings in distributed teams and contribute towards decision-making uncertainty. We uncover five notable inhibitors: role ambiguity, absence of a collective vision, transfer of ownership, lack of shared history, and incompatible personalities. 


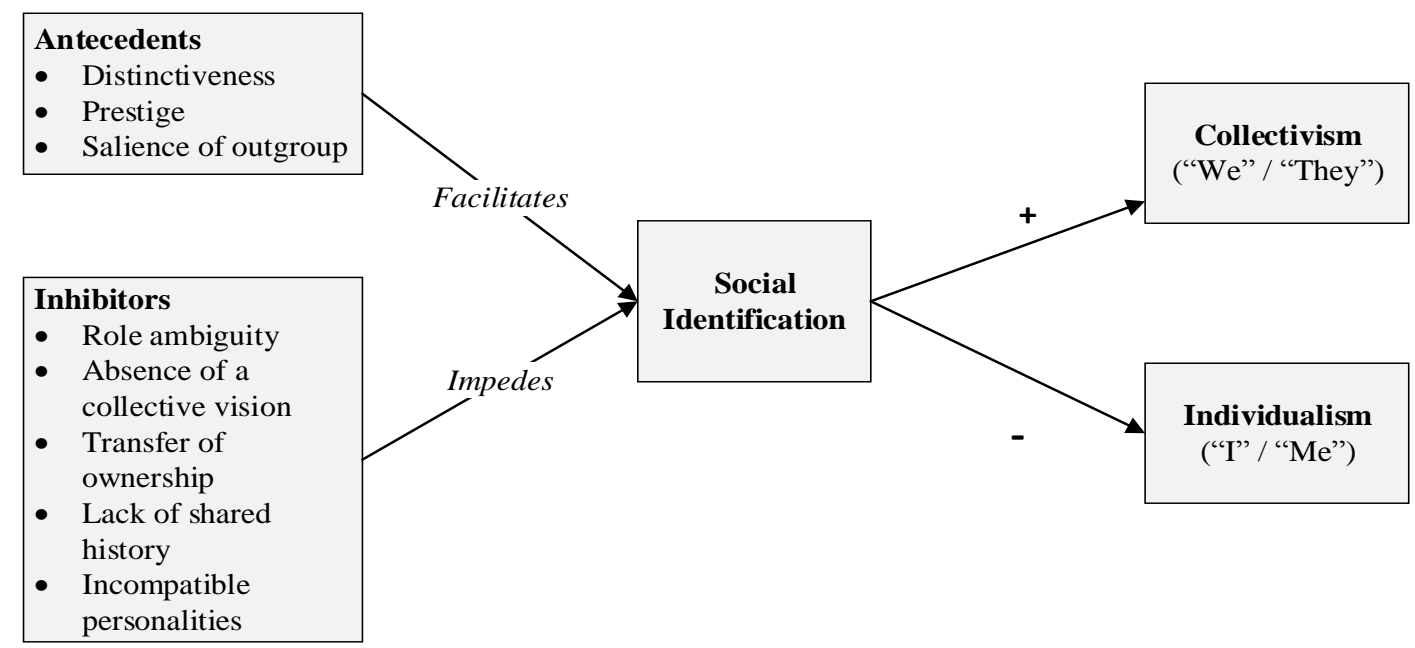

Figure 2: Antecedents and Inhibitors to Social Identification in Distributed Teams

We consequently propose an adapted version of SIT for the context of distributed teams which includes not just antecedents of collective identities (e.g. distinctiveness, prestige, salience of out-group), but also inhibitors which may impede the formation of social groupings and lead to the increased salience of individual identities. Figure 2 illustrates our extension to SIT which includes both antecedents and inhibitors to the emergence of social identification.

Our research also suggests that the dissolution of social groupings can impact distributed team performance, an issue which future research can seek to investigate further. Increased levels of individualism in the CDSS project fostered high levels of task conflict within the distributed team, and later negatively impacted project performance due to the inability of team members to fully resolve disagreements. The professional discourse of professions is also worth mentioning. The clinicians maintained a strong weight of imposition on decisions related to proposed policy change in the ICU ward and during discussions around how the CDSS system could affect change in current practices. I contrast, there was a high power distance between the developer and clinicians / scientists and he often felt unable to direct communications and assign responsibilities. Consequently, the developer's efforts at work-related communications were often unsuccessful and contrary to contrary to Postmes, et al. [25], did not support the emergence of collective identities.

Task conflict refers to where team members diverge in their shared understanding of and commitment to the tasks that need to be completed during a project $[40,41$, 42]. In the case study, extended periods of task conflict often proved difficult to resolve due to the rise of individualism in the team, where different team members each tried to assert their own goals and vision for the project. This in turn impeded progress and the finalisation of system requirements as team members could not reach agreement on aspects of the proposed solution. As a result, the project later encountered schedule delays when the distributed team struggled to deliver a working prototype within the initial timeline. It was necessary to extend the initial timeline as a result and budget overruns were encountered. In the end however, the developer decided to leave the project team and pursue other career opportunities, which may have been symptomatic of his increasing sense of isolation within the distributed team. The next section brings the paper to a close with a conclusion.

\section{Conclusion}

In this paper, we investigated the impact of social identification on decision-making process in distributed teams. Distributed decision-making practices are rife with uncertainty given the emergent nature of social identities in the teams and the lack of prior established social groupings. Using Social Identity Theory (SIT) as a theoretical lens, we analysed case study findings from a five-month information systems development project to uncover how social identifications occur in distributed teams and its impact on decision-making. Surprisingly, we find that despite the emergence of collective identities early on, decision-making processes increasingly became shaped by individual identities as social groupings started to dissolve. Based on these findings, our theoretical contribution centres on an 
extension to SIT which includes both antecedents of collective identities which were deductively characterised from existing literature (e.g. distinctiveness, prestige, salience of out-group), as well as inhibitors of social identification which were inductively derived from our findings (e.g. role ambiguity, absence of a collective vision, transfer of ownership, lack of shared history, and incompatible personalities). This contribution will provide scholars and practitioners with new insights into why collective identities may or may not form in distributed teams and the tension with individual identities among different professionals e.g. clinicians, developers, and scientists.

One limitation of our research was the unique context of the case study: the ICU ward of a local hospital. Future research can seek to generalize our findings by investigating social identification in other distributed team contexts. In addition, the co-location of certain members in the CDSS project may have shaped the emergence of certain in-groups and out-groups in the case. Findings suggest that the increased opportunities for face-to-face communication between the co-located developer, research nutritionist, and project officer may have supported the formation of social groupings separate from those who were based off-site. Future research can apply our research model to distributed teams with no co-located members e.g. virtual teams. Scholars may also seek to build on the qualitative approach adopted in this study by adopting quantitative techniques which seek causal inferences between inhibitors of social identification. For instance, experiments can be used to investigate the emergence of social identities among team members with and without shared histories, or role ambiguity.

Furthermore, we suggest that future research should study the different consequences of collective and individual identities (e.g. task conflict and team performance) and explore the relationships between antecedents and inhibitors. For instance, our findings suggest that some inhibitors may be mutually reinforcing such as the role ambiguity and the absence of a shared vision. Future research can also seek to examine the factors which cause identities to change over time. As evident from our case, social identification is not a static phenomenon, but rather it can adapt to changing circumstances, such as where one senior team member (e.g. the clinical lead) decreases their engagement with the project. For instance, agreeing clear role delineations and a collective vision early on may be instrumental in supporting collective identities as it avoids misunderstandings and guides the rules for decision making going forward. Additional antecedents and barriers which may contribute toward changes in social identification are also worthy of further exploration e.g. power distance, and communication styles. Finally, studies on the relationship between social identification and distributed team performance offer considerable potential for furthering our understanding of distributed collaboration, social identities, and the effectiveness or lack therefore, of such teams.

\section{References}

[1] E. Ó. Conchúir, P. J. Ågerfalk, H. H. Olsson and B. Fitzgerald, "Global software development: where are the benefits?", Communications of the ACM, 52 (2009), pp. 127131.

[2] A. J. Abugabah and O. Alfarraj, "Issues to Consider in Designing Health Care Information Systems: A User-centred Design Approach", electronic Journal of Health Informatics, 9 (2015), pp. 8.

[3] G. Robert, Participatory action research: using experience-based co-design to improve the quality of healthcare services, Understanding and Using Health Experiences-improving patient care, Oxford University Press, 2013.

[4] L. Locock, "Healthcare redesign: meaning, origins and application", Quality and Safety in Health Care, 12 (2003), pp. 53-57.

[5] J. Conklin, Dialogue mapping: Building shared understanding of wicked problems, Wiley, West Sussex, UK, 2005.

[6] K. Grint, Wicked problems and clumsy solutions: the role of leadership, The new public leadership challenge, Springer, 2010, pp. 169-186.

[7] M. Kleinsmann and R. Valkenburg, "Barriers and enablers for creating shared understanding in co-design projects", Design Studies, 29 (2008), pp. 369-386.

[8] E. A. C. Bittner and J. M. Leimeister, "Creating shared understanding in heterogeneous work groups: Why it matters and how to achieve it", Journal of Management Information Systems, 31 (2014), pp. 111-144.

[9] S. McCarthy, P. O'Raghallaigh, C. Fitzgerald and F. Adam, Exploring the Nuances of 'Wickedness' in Information Systems Development, Hawaii International Conference on Systems Science, 2018.

[10] S. Sarker and S. Sahay, "Understanding virtual team development: An interpretive study", Journal of the association for information systems, 4 (2003), pp. 1. [11] H. Holmström, B. Fitzgerald, P. J. Ågerfalk and E. Ó. Conchúir, "Agile practices reduce distance in global software development", Information systems management, 23 (2006), pp. 7-18.

[12] B. E. Ashforth and F. Mael, "Social identity theory and the organization", Academy of management review, 14 (1989), pp. 20-39.

[13] H. P. Andres, "A comparison of face-to-face and virtual software development teams", Team Performance Management, 8 (2002), pp. 39-48brue.

[14] P. R. Carlile, "Transferring, translating, and transforming: An integrative framework for managing knowledge across boundaries", Organization science, 15 (2004), pp. 555-568. 
[15] S. McCarthy, P. O'Raghallaigh, C. Fitzgerald and F. Adam, Towards a framework for shared understanding and shared commitment in agile distributed ISD project teams, Proceedings of the 27th European Conference on Information Systems, AIS Electronic Library (AISeL), Stockholm, Sweden, 2019.

[16] M. Carter and V. Grover, "Me, My Self, and I (T): Conceptualizing Information Technology Identity and its Implications", Mis Quarterly, 39 (2015).

[17] E. A. Whitley, U. Gal and A. Kjaergaard, "Who do you think you are? A review of the complex interplay between information systems, identification and identity", European Journal of Information Systems, 23 (2014), pp. 17-35. [18] R. M. Kramer, P. Pommerenke and E. Newton, "The social context of negotiation: Effects of social identity and interpersonal accountability on negotiator decision making", Journal of Conflict Resolution, 37 (1993), pp. 633-654. [19] D. J. Benjamin, J. J. Choi and A. J. Strickland, "Social identity and preferences", American Economic Review, 100 (2010), pp. 1913-28.

[20] S. A. Haslam, M. K. Ryan, T. Postmes, R. Spears, J. Jetten and P. Webley, "Sticking to our guns: Social identity as a basis for the maintenance of commitment to faltering organizational projects", Journal of Organizational Behavior: The International Journal of Industrial, Occupational and Organizational Psychology and Behavior, 27 (2006), pp. 607628.

[21] P. J. Hinds and M. Mortensen, "Understanding conflict in geographically distributed teams: The moderating effects of shared identity, shared context, and spontaneous communication", Organization science, 16 (2005), pp. 290307.

[22] H. Tajfel, J. C. Turner, W. G. Austin and S. Worchel, "An integrative theory of intergroup conflict", Organizational identity: A reader, 56 (1979), pp. 65.

[23] T. Parsons, The Social system, Routledge, London, 1951.

[24] E. Whitworth and R. Biddle, The social nature of agile teams, Agile 2007 (AGILE 2007), IEEE, 2007, pp. 26-36.

[25] T. Postmes, M. Tanis and B. De Wit, "Communication and commitment in organizations: A social identity approach", Group Processes \& Intergroup Relations, 4 (2001), pp. 227-246.

[26] S. Nevin, R. Gleasure, P. O'Reilly, J. Feller, S. Li and J. Cristoforo, Social identity and social media activities in equity crowdfunding, Proceedings of the 13th International Symposium on Open Collaboration, 2017, pp. 1-8.

[27] S. Ghobadi and L. Mathiassen, "Perceived barriers to effective knowledge sharing in agile software teams", Information systems journal, 26 (2015), pp. 95-125. [28] P. J. Ågerfalk, B. Fitzgerald, H. Holmstrom Olsson, B. Lings, B. Lundell and E. Ó Conchúir, A framework for considering opportunities and threats in distributed software development, International Workshop on Distributed Software Development Austrian Computer Society, Paris, Aug. 29, 2005, 2005.

[29] P. Vahtera, P. J. Buckley, M. Aliyev, J. Clegg and A. R. Cross, "Influence of social identity on negative perceptions in global virtual teams", Journal of International Management, 23 (2017), pp. 367-381.
[30] R. Katz, Time and work: Toward an integrative perspective, in B. M. S. L. L. Cummings, ed., Research in organizational behavior, JAI Press, Greenwich, CT, 1980, pp. 81-127.

[31] G. Walsham, "Interpretive case studies in IS research: nature and method", European Journal of information systems, 4 (1995), pp. 74-81.

[32] P. Darke, G. Shanks and M. Broadbent, "Successfully completing case study research: combining rigour, relevance and pragmatism", Information systems journal, 8 (1998), pp. 273-289.

[33] M. B. Miles and A. M. Huberman, Qualitative data analysis: An expanded sourcebook, Sage, Beverly Hills, 1994.

[34] K. Breu and C. J. Hemingway, "Making organisations virtual: the hidden cost of distributed teams", Journal of Information Technology, 19 (2004), pp. 191-202.

[35] T. R. Kayworth and D. E. Leidner, "Leadership effectiveness in global virtual teams", Journal of management information systems, 18 (2002), pp. 7-40.

[36] R. E. Potter, R. A. Cooke and P. A. Balthazard, "Virtual team interaction: assessment, consequences, and management", Team Performance Management, 6 (2000), pp. 131-137.

[37] M. R. Barrick and M. K. Mount, "The big five personality dimensions and job performance: a metaanalysis", Personnel psychology, 44 (1991), pp. 1-26. [38] J. E. Hoch and J. H. Dulebohn, "Team personality composition, emergent leadership and shared leadership in virtual teams: A theoretical framework", Human Resource Management Review, 27 (2017), pp. 678-693.

[39] C. C. Cogliser, W. L. Gardner, M. B. Gavin and J. C. Broberg, "Big five personality factors and leader emergence in virtual teams: Relationships with team trustworthiness, member performance contributions, and team performance", Group \& Organization Management, 37 (2012), pp. 752-784. [40] C. K. De Dreu and L. R. Weingart, "Task versus relationship conflict, team performance, and team member satisfaction: a meta-analysis", Journal of Applied Psychology, 88 (2003), pp. 741.

[41] J.-L. Farh, C. Lee and C. I. Farh, "Task conflict and team creativity: a question of how much and when", Journal of Applied Psychology, 95 (2010), pp. 1173.

[42] J. B. Windeler, L. M. Maruping, L. P. Robert and C. K. Riemenschneider, "E-profiles, conflict, and shared understanding in distributed teams", Journal of the Association for Information Systems, 16 (2015), pp. 608. 